Genetica, Vol. 138(7), pp. 695-708 (2010)

\title{
Mammalian Carboxylesterase 3: Comparative Genomics and Proteomics
}

\author{
Roger S Holmes ${ }^{1-4}$, Laura A Cox ${ }^{1,2}$ and John L VandeBerg ${ }^{1,2}$ \\ ${ }^{1}$ Department of Genetics and ${ }^{2}$ Southwest National Primate Research Center, Southwest Foundation for \\ Biomedical Research, San Antonio, TX, USA, and ${ }^{3}$ School of Biomolecular and Physical Sciences, Griffith \\ University, Nathan, QLD, Australia
}

${ }^{4}$ Corresponding Author:

Roger S Holmes, D.Sc.

Department of Genetics

Southwest National Primate Research Center

Southwest Foundation for Biomedical Research

San Antonio, TX, USA 78227

Email: rholmes@ sfbrgenetics.org

Phone: $210-258-9687$

Fax: $210-258-9600$

Keywords: Mammals; amino acid sequence; carboxylesterase; evolution; gene duplication.

Running Head: Mammalian CES3: comparative genomics and proteomics 


\section{Summary}

At least five families of mammalian carboxylesterases (CES) catalyse the hydrolysis or transesterification of a wide range of drugs and xenobiotics and may also participate in fatty acyl and cholesterol ester metabolism. In this study, in silico methods were used to predict the amino acid sequences, secondary and tertiary structures, and gene locations for CES3 genes and encoded proteins using data from several mammalian genome projects. Mammalian CES3 genes were located within a CES gene cluster with CES2 and CES6 genes, usually containing 13 exons transcribed on the positive DNA strand. Evidence is reported for duplicated CES3 genes for the chimp and mouse genomes. Mammalian CES3 protein subunits shared 58-97\% sequence identity and exhibited sequence alignments and identities for key CES amino acid residues as well as extensive conservation of predicted secondary and tertiary structures with those previously reported for human CES1. The human genome project has previously reported CES3 mRNA isoform expression in several tissues, particularly in colon, trachea and in brain. Predicted human CES3 isoproteins were apparently derived from exon shuffling and are likely to be secreted extracellularly or retained within the cytoplasm. Mouse CES3-like transcripts were localized in specific regions of the mouse brain, including the cerebellum, and may play a role in the detoxification of drugs and xenobiotics in neural tissues and other tissues of the body. Phylogenetic analyses demonstrated the relationships and potential evolutionary origins of the mammalian CES3 family of genes which were related to but distinct from other mammalian CES gene families. 


\section{Introduction}

At least five families of mammalian carboxylesterases (CES; E.C.3.1.1.1) have been reported (Holmes et al., 2008a,b; 2009a-d) including CES1, the major liver enzyme (Munger et al., 1991; Shibata et al. 1993; Ghosh 2000; Holmes et al., 2009a); CES2, the major intestinal enzyme (Langmann et al. 1997; Schewer et al. 1997; Holmes et al., 2009a); CES3, expressed in liver, colon and brain (Sanghani et al. 2004; Holmes et al., 2009a-c); CES5 (also called CES7 or cauxin), a major urinary protein of the domestic cat (Miyazaki et al. 2003; 2006; Holmes et al., 2008b); and CES6, a predicted CES-like enzyme in brain (Clark et al., 2003; Holmes et al., 2009d). These enzymes catalyse hydrolytic and transesterification reactions with xenobiotics, anticancer prodrugs, and narcotics (Satoh \& Hosokawa 1998; 2006; Satoh et al. 2002; Ohtsuka et al. 2003; Redinbo \& Potter 2005), and detoxify organophosphates and insecticides (Ahmad \& Forgash 1976; Leinweber 1987). CES may also catalyse several cholesterol and fatty acid metabolic reactions (Ghosh 2000; Tsujita \& Okuda 1993; Becker et al. 1994; Hosokawa et al. 2007; Diczfalusy et al. 2001), the conversion of lung alveolar surfactant (Ruppert et al. 2006) and assist with the assembly of low density lipoprotein particles in liver (Wang et al. 2007).

Structures for several human and animal $C E S$ genes have been determined, including human (Becker et al. 1994; Langmann et al. 1997; Ghosh 2000; Marsh et al. 2004) and rodent CES1 and CES2 'like' genes (Ghosh et al. 1995; Dolinsky et al. 2001; Hosokawa et al. 2007). Predicted gene structures have also been described for other mammalian CES gene families, including CES1, CES2 and CES5 genes, which are localized in two contiguous CES gene clusters on human (chromosome 16), horse (chromosome 3), cow (chromosome 18) and opossum (chromosome 1) genomes (Holmes et al. 2008a; 2009a-c). Mammalian CES genes usually contain 12 to 14 exons of DNA encoding CES enzyme sequences which may undergo exon shuffling generating several CES isoproteins in each case (Thierry-Mieg and Thierry-Mieg, 2006). There are similarities for the exon boundaries for each of the mammalian CES genes (Holmes et al., 2008a,b; 2009a-d) as well as significant sequence identities, especially for key regions previously identified for the major human liver CES1 (Bencharit et al. 2003; 2006; Fleming et al. 2005). Three-dimensional structural analyses of human CES1 have identified three major ligand binding sites, including the promiscuous active site, 'side door' and 'Z-site', where substrates, fatty acids and cholesterol analogues respectively, are bound; and the 'gate', reportedly functioning in product release (Bencharit et al. 2003; 2006; Fleming et al. 2005).

This paper reports the predicted gene structures and amino acid sequences for several mammalian CES3 genes and proteins, the predicted secondary and tertiary structures for mammalian CES3 protein subunits, and the 
structural, phylogenetic and evolutionary relationships for these genes and enzymes with those for other mammalian CES gene families.

\section{Methods}

\section{In silico mammalian $C E S$ gene and protein identification.}

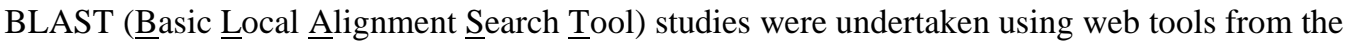
National Center for Biotechnology Information (NCBI) (http://blast.ncbi.nlm.nih.gov/Blast.cgi) (Altschul et al, 1997). Protein BLAST analyses used mammalian CES amino acid sequences previously described (Table 1). Non-redundant protein sequence databases for several mammalian genomes were examined using the blastp algorithm, including human (Homo sapiens) (International Human Genome Sequencing Consortium, 2001); chimp (Pan troglodytes) (Chimpanzee Genome Analysis Consortium, 2005); orangutan (Pongo abelii) (http://genome.wustl.edu) ; the cow (Bos Taurus) (Bovine Genome Project, 2008); horse (Equus caballus) (Horse Genome Project, 2008); mouse (Mus musculus) (Mouse Sequencing Consortium, 2002); and opossum (Monodelphis domestica) (Mikkelsen et al., 2007). This procedure produced multiple BLAST 'hits' for each of the protein databases which were individually examined and retained in FASTA format, and a record kept of the sequences for predicted mRNAs and encoded CES-like proteins. These records were derived from annotated genomic sequences using the gene prediction method: GNOMON and predicted sequences with high similarity scores for human CES6. Predicted CES3-like protein sequences were obtained in each case and subjected to in silico analyses of predicted protein and gene structures.

BLAT analyses were subsequently undertaken for each of the predicted CES3 amino acid sequences using the UC Santa Cruz web browser [http://genome.ucsc.edu/cgi-bin/hgBlat] (Kent et al. 2003) with the default settings to obtain the predicted locations for each of the mammalian CES3 genes, including predicted exon boundary locations and gene sizes. BLAT analyses were similarly undertaken of CES1, CES2, CES5 and CES6-like human genes using previously reported sequences for encoded CES subunits in each case (see Table 1). Structures for human CES3 isoforms (splicing variants) were obtained using the AceView website (http://www.ncbi.nlm.nih.gov/IEB/Research/Acembly/index.html?human) to examine predicted gene and protein structures using the human $C E S 3$ cDNA sequence (GenBank NM024922) to interrogate this database of human mRNA sequences (Thierry-Mieg and Thierry-Mieg, 2006).

BLAT (BLAST-Like Alignment Tool) in silico studies were undertaken using the UC Santa Cruz web browser [http://genome.ucsc.edu/cgi-bin/hgBlat] (Kent et al. 2003) with the default settings. UniProtKB/Swiss-Prot 
Database [http://au.expasy.org] and GenBank [http://www.ncbi.nlm.nih.gov/Genbank/] sequences for human, orangutan and mouse CES sequences (Table 1) were used to interrogate human, chimp, orangutan, horse, cow, mouse and opossum genome sequences. Gene locations, predicted gene structures and CES protein subunit sequences were observed for each CES examined for those regions showing identity with the respective mammalian CES gene products.

\section{Predicted Structures and Properties of Mammalian CES Subunits.}

Predicted secondary and tertiary structures for human and other mammalian CES-like subunits were obtained using the PSIPRED v2.5 web site tools provided by Brunel University [http://bioinf.cs.ucl.ac.uk/psipred/psiform.html] (McGuffin et al. 2000) and the SWISS MODEL web tools [http://swissmodel.expasy.org/], respectively (Guex \& Peitsch 1997; Kopp \& Schwede 2004). The reported tertiary structure for the rabbit CES1 4-piperidino-piperidine complex (Bencharit et al., 2003) served as the reference for the predicted human CES3 tertiary structure, with a modeling range of residues 34 to 553 . Theoretical isoelectric points and molecular weights for mammalian CES3 subunits were obtained using Expasy web tools (http://au.expasy.org/tools/pi_tool.html). SignalP $3.0 \mathrm{web}$ tools were used to predict the presence and location of signal peptide cleavage sites (http://www.cbs.dtu.dk/services/SignalP/) for each of the predicted mammalian CES sequences (Emanuelsson et al 2007). The NetNGlyc 1.0 Server was used to predict potential N-glycosylation sites for human CES and mammalian CES3 subunits (http://www.cbs.dtu.dk/services/NetNGlyc/). Predictions of subcellular locations for mammalian CES3 'like' enzymes and for human CES1, CES2, CES5 and CES6 were conducted using PSORT 11 (http://psort.ims.u-tokyo.ac.jp/form2.html) (Horton \& Nakai, 1997).

\section{Mouse Brain CES3 Expression}

The Allen Mouse Brain Atlas was interrogated for cellular transcription of the mouse CES3 gene using the GenBank BC061004 sequence (see Table 1) (Lein et al., 2007). Data for sagittal sections of mouse brain were examined and recorded for mouse CES3 transcripts using web tools available on the Allen Brain Atlas web site (http://www.brain-map.org).

\section{Phylogenetic Studies and Sequence Divergence}

Phylogenetic trees were constructed using an amino acid alignment from a ClustalW-derived alignment of CES protein sequences, obtained with default settings and corrected for multiple substitutions (Chenna et al. 2003) [http://www.ebi.ac.uk/clustalw/]. An alignment score was calculated for each aligned sequence by first calculating a pairwise score for every pair of sequences aligned. Alignment ambiguous regions, including the amino and carboxyl 
termini, were excluded prior to phylogenetic analysis yielding alignments of 453 residues for comparisons of mammalian CES1, CES2, CES3, CES5 and CES6 sequences (Table 1). Pairwise scores were calculated using the number of identities in the best alignment divided by the number of residues compared. Scores were initially calculated as percent identity scores and were converted to distances by dividing by 100 and subtracting from 1.0 to give the number of differences per site. The extent of divergence for the mammalian CES3-like subunits, and the human CES1, CES2, CES5 and CES6 subunits were determined using the SIM-Alignment tool for Protein Sequences [http://au.expasy.org/tools/sim-prot.html] (Schwede et al. 2003).

\section{Results and Discussion}

\section{Alignments of Human CES Subunits and Mammalian CES3 Amino Acid Sequences.}

The deduced amino acid sequences for horse, cow and mouse CES3-like subunits are shown in Figure 1 together with the previously reported sequences for human CES1 (Munger et al. 1991; Shibata et al. 1993); human CES2 (Langmann et al. 1997; Schewer et al. 1997); human CES3 (Sanghani et al. 2004 ); human CES5 (Holmes et al., 2008b); and human CES6 (Holmes et al., 2009d) (Table 1). Alignments of the human and other mammalian CES3 subunits examined in this figure showed between 68-77\% sequence identities, suggesting that these CES protein subunits are products of the same family of genes, whereas sequence alignments of mammalian CES3 subunits with human CES1, CES2, CES5 and CES6 subunits exhibited lower levels of sequence identities with human CES3 (47\%, 50\%, 48\% and 45\%, respectively), indicating that these are members of distinct CES families (Table 2).

The amino acid sequence for human CES3 contained 571 residues whereas other predicted mammalian CES3 subunits contained fewer amino acids: 570 residues for cow and horse CES3; 554 residues for mouse CES3; and 568 residues for mouse CES3L (Figure 1). Previous studies on human CES1 have identified key residues which contribute to the catalytic, subcellular localization, oligomeric and regulatory functions for this enzyme (sequence numbers refer to human CES1). These include the catalytic triad for the active site (Ser228; Glu345; His458) (Cygler et al. 1993); microsomal targeting sequences, including the hydrophobic N-terminus signal peptide (von Heijne 1983; Zhen et al. 1995; Potter et al. 1998) and the C-terminal endoplasmic reticulum (ER) retention sequence (His-Ile-Glu-Leu) (Robbi \& Beaufay 1983); disulfide bond forming residues (Cys95/Cys123 and Cys280/Cys291) (Lockridge et al. 1987); and ligand binding sites, including the 'Z-site' (Gly358), the 'side door' (Val424-Met425Phe426) and the 'gate' (Phe551) residues. Identical residues were observed for each of the mammalian CES3 subunits for the active site triad and disulfide bond forming residues for human CES1although several changes were 
observed for the corresponding residues for CES3 subunits of other key human CES1 residues: the 'side-door' identified for human CES1 (Val424-Met425-Phe426) (Bencharit et al., 2003; 2006) has a Val416-Phe417-Ile418 sequence for human CES3; the 'Z-site' (Gly358 for human CES1) has been changed to Ser355 for human CES3, although other mammalian CES3 sequences examined have retained a glycine residue at this position; the hydrophobic N-terminal sequence for mammalian CES3 sequences has undergone major changes however this region retains in each case a predicted signal peptide property; the mammalian CES3 C-terminal sequences have undergone significant changes in sequence (QEDL, QEEL or PEEL) in comparison with human CES1 (HIEL). This may be responsible for a change in the predicted microlocalization for the CES3 subunits (secreted or extracellular enzymes), as compared with human CES1, which is retained by the endoplasmic reticulum (Table 1). The 'gate' residue has also undergone changes for the mammalian CES3 sequences examined from Phe551 (CES1) to Tyr (human and horse CES3) or Leu (cow and mouse CES3).

Other key human CES1 sequences included two charge clamps which are responsible for subunit-subunit interaction, namely residues Lys78/Glu183 and Glu72/Arg193 (Bencharit et al. 2003; 2006; Fleming et al. 2005). Predicted mammalian CES3 subunit sequences for these sites indicated that only one of the charge clamps would be retained for human CES3 subunits: Arg88/Glu191 (Figure 1), whereas other mammalian CES3 subunits examined showed no potential for forming charge clamps at the corresponding sequence positions. Previous reports have shown that human and baboon CES2 subunits, which lack these charge clamp residues, behave as monomers (Pindel et al. 1997; Holmes et al., 2009a). With the exception of human CES3, the mammalian CES3 sequences have undergone amino acid substitutions for those residues which contribute to the oligomeric subunit structure for human CES1. The identified human CES1 charge clamp residues Lys78/Glu183 and Glu72/Arg193 have other residues at the corresponding sites (Arg88/191Lys and Gln82/Ala194 for the horse CES3 sequence) (Figure 1), and it is likely that these mammalian CES3 subunits are also monomeric in subunit structure. This may have a major influence on the kinetics and biochemical roles for mammalian CES3 since three dimensional studies have suggested that ligand binding to the human CES1 'Z-site' shifts the trimer-hexamer equilibrium towards the trimer facilitating substrate binding and enzyme catalysis (Redinbo \& Potter 2005). This property is unlikely to be shared by mammalian CES3 which is expected to display distinct kinetic properties to the oligomeric CES1 enzyme.

The N-glycosylation site reported for human CES1 at Asn79-Ala80-Thr81 (Kroetz et al. 1993; Bencharit et al. 2003; 2006; Fleming et al. 2005) has not been retained for any of the mammalian CES3 sequences, although additional potential N-glycosylation sites were observed at one or several positions (Table 3). Given the reported role of the $\mathrm{N}$-glycosylated carbohydrate group in contributing to mammalian CES stability and maintaining catalytic 
efficiency (Kroetz et al. 1993), this property may be shared by the mammalian CES3 subunits as well, especially for those containing multiple potential sites for N-glycosylation, such as the mouse CES3L sequence, which contains four such sites.

Predicted Secondary and Tertiary Structures for Mammalian CES3 Subunits.

Analyses of predicted secondary structures for mammalian CES3 sequences were compared with the previously reported secondary structure for human CES1 (Bencharit et al., 2003; 2006) and with those predicted for human CES2, CES5 and CES6 (Holmes et al., 2009a) (Figure 1). Similar $\alpha$-helix $\beta$-sheet structures were observed for all of the mammalian CES3 and human CES gene products examined. Consistent structures were apparent near key residues or functional domains including the $\alpha$-helix within the $\mathrm{N}$-terminal signal peptide; the $\beta$-sheet and $\alpha$ helix structures near the active site Ser228 (human CES1) and 'Z-site' (Glu354/Gly356 respectively); the $\alpha$-helices bordering the 'side door' site; and the $\alpha$-helix containing the 'gate' residue (Phe551 for human CES1). In addition, two random coil regions (residues 51-115 and 169-188 for human CES1) were predominantly retained for all forms of mammalian CES3 examined which have been shown for human CES1 to contain 2 charge clamps sites: (Lys79/Glu183 and Glu73/Arg186); an N-glycosylation site at Asn79-Ala80-Thr81; a second potential Nglycosylation site for human CES2, and one of the disulfide bridges (87Cys /117Cys) reported for human CES1. The human CES5 secondary structure, however, predicted an additional helix at the hydrophobic C-termini, in comparison with mammalian CES3 C-terminal sequences. In addition, the predicted 3-D structure for human CES3 is similar to the reported for human CES1 (Bencharit et al., 2003; 2006) (Figure 3). These were based on structures reported for residues 21-553 of human CES1 and a predicted structure for residues 34-553 of human CES3. The single helix and following two $\beta$-sheet structures at the C-termini (shown in red at the top) for the human CES1 and CES3 subunits are readily apparent, as are four $\beta$-sheet structures at the N-termini of the CES subunits (shown in blue at the base), in each case. It is apparent that human CES3 is likely to be highly similar in its secondary and tertiary structure to that reported for human CES1.

\section{Predicted Gene Locations and Exonic Structures for Mammalian CES3 Genes.}

Table 1 summarizes the predicted locations for mammalian CES3 genes based upon BLAT interrogations of several mammalian genomes using the reported sequences for human CES3, mouse CES3 and CES3L, and the predicted sequences for horse and cow CES3 and the UC Santa Cruz Web Browser (Kent et al. 2003). The predicted mammalian CES3 genes were located in a CES2/CES3/CES6 gene cluster in each case, although the gene order underwent changes for different species. In addition, mouse showed evidence of duplicate CES3 genes, with 
predicted CES3 and CES3L genes being located within a four CES gene cluster on chromosome 8: CES2-CES3CES3L-CES6 (Table 1). Chimp CES3 also provided evidence for duplicate forms of this gene on chromosome 16 but with a changed order of genes: CES6-CES3L-CES2-CES3 (Table 1). BLAT interrogations of mammalian genomes with the corresponding CES sequences suggested that the CES2-CES3-CES6 gene cluster was syntenic for chromosomes 16 (human, chimp and orangutan), 3 (horse), 18 (cow), 8 (mouse) and 1 (opossum), respectively.

With the exception of the opossum CES3 gene, mammalian CES3 'like' genes were apparently transcribed on the positive strand, as for the human CES2 and CES6 genes. In contrast, human CES1 and CES5 genes were transcribed on the negative strand (Table 1). Figure 1 summarizes the predicted exonic start sites for cow, horse and mouse CES3 genes with each having 13 exons, in identical or similar positions to those predicted for the human CES3 gene (Holmes et al., 2009a). The predicted chimp CES3L gene however exhibited only 11 predicted exons. Human CES1 (Munger et al. 1991; Shibata et al. 1993), CES2 (Tang et al., 2008), CES5 (Ota et al., 2004) and CES6 (Holmes et al., 2009d) genes contained 14, 12, 13 and 14 exons respectively (Figure 1), in similar positions to those predicted for the mammalian CES3 genes (Figure 1).

Figure 4 shows the predicted nucleotide sequences for exons 2-4 and introns 2 and 3 of mouse CES3 and CES3L genes. The sequences for the exons were $98 \%$ identical with nearly identical amino acid sequences involving five amino acid substitutions for these genes, whereas mouse CES3 and CES3L introns 2 and 3 showed distinct nucleotide sequences which were $85 \%$ and $94 \%$ identical, respectively. In addition, BLAT analyses of the mouse genome revealed distinct but closely localized predicted positions for these genes, being separated by $\sim 26$ kilobases of DNA on chromosome 8 (Table 1). These data support an hypothesis for two closely related and localized CES3like genes in the mouse, for which the subunits have been previously designated as esterase-31 (also called CES3) (Aida et al., 1993) and esterase-31L (also called CES3L) (Mouse Genome Consortium, 2004).

\section{Mouse Brain CES3 and CES3L Expression.}

Figure 5 shows a sagittal section of mouse brain examining the distribution of CES3 and CES3L transcripts (GenBank mRNA $\underline{\mathrm{BC} 061004}$ and $\underline{\mathrm{BC} 019047)}$ ) within different regions of the brain (provided by the Allen Institute for Brain Science) (Lein et al., 2007). The cerebellum folds exhibited highest staining levels for both transcripts although staining was observed throughout the brain, including the hippocampus, amygdalar nuclei, the olfactory bulb, the cortex, the pons and the medulla regions.

The differential tissue and subcellular distributions of CES family members may assist in determining the differential roles of CES family members within mammalian organisms. Mammalian liver is predominantly 
responsible for drug and xenobiotic clearance from the body with CES1 and CES2 (with CES1 > CES2) playing major roles, following absorption of drugs and xenobiotics into the circulation (Pindel et al. 1997; Imai 2006). Mammalian intestine (with CES2 > CES1) is predominantly responsible for first pass clearance of several drugs and xenobiotics, with the activity occurring mostly in the ileum and jejunum and processed via CES2 (Imai et al. 2003). CES1 and CES2 also serve different roles in prodrug activation, as shown for the anti-cancer drug irinotecan (CPT11) which is converted to its active form SN-38 predominantly by CES2 (Humerickhouse et al. 2000; Xu et al. 2002). In contrast with CES1 and CES2, mammalian CES5 is predominantly expressed in peripheral tissues, including brain, kidney, lung and testis (Thierry-Mieg and Thierry-Mieg, 2006), and in cat, is a secreted form of CES enzyme appearing in cat urine (Miyazaki et al. 2003; 2006). Mammalian CES5 may serve in two major roles within mammalian fluids and peripheral tissues, including regulating the production of a pheromone precursor in urine (Miyazaki et al. 2003; 2006) and contributing to lipid and cholesterol transfer processes within male reproductive fluids (Ecroyd et al. 2005).

The metabolic role(s) for mammalian CES3 has not been extensively investigated although the enzyme is capable of activating prodrugs such as irinotecan (Sanghani et al., 2004) and the gene is expressed as distinct isoforms in tissues of the body, including the colon, placenta and neural tissues, such as the cerebellum and hippocampus (Figure 2; Table 4) (Thierry-Mieg and Thierry-Mieg, 2006). Human CES3 mRNAs encode isoforms which are predicted to be either secreted or extracellular (CES3a-c), cytosolic (CES3d) or extracellular (CES3e-u), and may play distinct roles in carboxyl-ester metabolism in the body. A comparison of the predicted cellular locations for mammalian CES3 reveals that it is likely to be extracellular (including the cell wall) in primate (human, chimp and orangutan) and mouse tissues, whereas horse and bovine CES3 are predicted to be localized in the endoplasmic reticulum, which is comparable with human CES1 and CES2. The extracellular locations predicted for human and mouse CES3 may reflect distinct roles for this enzyme in drug metabolism within peripheral tissues of the body.

\section{Phylogeny and Divergence of CES3 and Other Mammalian CES Sequences.}

A phylogenetic tree (Figure 6) was calculated by the progressive alignment of human, chimp, orangutan, horse, cow, mouse and opossum CES3-like amino acid sequences with human CES1, CES2, CES5 and CES6 sequences. The phylogram showed clustering of all of the CES3-like sequences which were distinct from the other human CES families. In addition, the CES3 and CES3L chimp and mouse sequences showed clustering with the primate and mouse CES3-like genes, respectively which is consistent with these genes being products of recent 
duplication events during mammalian evolution. Holmes et al (2008a) have previously demonstrated that the gene duplication events which generated the ancestral mammalian CES1, CES2, CES3, CES5 and CES6 genes predated the common ancestor for marsupial and eutherian mammals [estimated at 173-193 million years ago by Woodburne et al (2003)], and appear to coincide with the early diversification of tetrapods approximately 350-360 million years ago ((Donoghue \& Benton, 2007). The mammalian CES3 family of genes may therefore be considered to be of an ancient origin, well prior to the appearance of mammals in evolutionary time.

In conclusion, the results of the present study indicate that mammalian CES3 genes and encoded CES3 enzymes represent a distinct $C E S$ gene and enzyme family which share key conserved sequences and structures that have been reported for human CES1 and have family specific sequences consistent with the oligomeric and monomeric subunit structures for CES1 and CES3, respectively. This study also reports that chimp and mouse genomes contain at least two CES3 'like' genes, which are located in tandem with the CES2 and CES6 genes, and with the more distantly located CES1 and CES5 genes on chromosomes 16 and 8, respectively. Predicted secondary structures and tertiary structures for mammalian CES3 subunits showed a high degree of conservation with human CES1. Phylogeny studies using several mammalian CES3 subunits (human, chimp, orangutan, mouse, horse, cow and opossum) indicated that CES3 ' like' genes have apparently appeared during mammalian evolution well prior to the eutherian and marsupial common ancestor more than 170 million years ago, which is consistent with previous studies (Holmes et al, 2008a).

\section{Acknowledgements:}

This project was supported by NIH Grants P01 HL028972 and P51 RR013986. In addition, this investigation was conducted in facilities constructed with support from Research Facilities Improvement Program Grant Numbers 1 C06 RR13556, 1 C06 RR15456, 1 C06 RR017515.

\section{REFERENCES}

Ahmad S, Forgash AJ (1976) Nonoxidative enzymes in the metabolism of insecticides. Drug Metab Revs 5: 141-64.

Altschul F, Vyas V, Cornfield A, Goodin S, Ravikumar TS, Rubin EH, Gupta E (1990) Basic local alignment search tool. J Mol Biol 215: 403-410.

Becker A, Bottcher A, Lackner KJ, Fehringer P, Notka F, Aslandis C, Schmithz C (1994) Purification, cloning and expression of a human enzyme with acyl coenzyme A: cholesterol acyltransferase activity, which is identical to liver carboxylesterase. Arterioscler Thromb 14: 1346-1355.

Bencharit S, Edwards CC, Morton CL, Howard-Williams EL, Kuhn P, Potter PM, Redinbo MR (2006) Multisite promiscuity in the processing of endogenous substrates by human carboxylesterase 1. J Mol Biol 363 : 201-214. 
Bencharit S., Morton C.L., Xue Y, Potter PM, Redinbo MR (2003) Structural basis of heroin and cocaine metabolism by a promiscuous human drug-processing enzyme. Nature Struct Biol 10: 349-356.

Bovine Genome Project (2008) http://hgsc.bcm.tmc.edu/projects/bovine

Chenna R., Sugawara H., Koike T, Lopez R, Gibson TJ, Higgins DJ, Thompson JD (2003) Multiple sequence alignment with the Clustal series of programs. Nucleic Acids Res 31:3497-3500.

Chimpanzee Sequencing and Analysis Consortium (2005) Initial sequence of the chimpanzee genome and comparison with the human genome. Nature 437: 69-87.

Clark HF, Gurney AL, Abaya E, Baker K, Baldwin D, Brush J, Chen J, Chow B, Chui C, Crowley C, Currell B, Deuel B, Dowd P, Eaton D, Foster J, Grimaldi C, Gu Q, Hass PE, Heldens S, Huang A, Kim HS, Klimowski L, Jin Y, Johnson S, Lee J, Lewis L, Liao D, Mark M, Robbie E, Sanchez C, Schoenfeld J, Seshagiri S, Simmons L, Singh J, Smith V, Stinson J, Vagts A, Vandlen R, Watanabe C, Wieand D, Woods K, Xie MH, Yansura D, Yi S, Yu G, Yuan J, Zhang M, Zhang Z, Goddard A, Wood WI, Godowski P, Gray A (2003) The secreted protein discovery initiative (SPDI), a large-scale effort to identify novel human secreted and transmembrane proteins: a bioinformatics assessment. Genome Res 13: 226-2270.

Cygler M, Schrag JD, Sussman JL, Harel M, Silman I, Gentry MK, Dostor BP (1993) Relationship between sequence conservation and three-dimensional structure in a large family of esterases, lipases and related proteins. Protein Science 2: 366-382.

Diczfalusy MA, Bjorkkem I, Einarsson C, Hillebrant CG, Alexson SE (2001) Characterization of enzymes involved in formation of ethyl esters of long-chain fatty acids. J Lipid Res 42: 1025-1032.

Dolinsky VW, Sipione S, Lehner R et al (2001) The cloning and expression of murine triacylglycerol hydrolase cDNA and the structure of the corresponding gene. Biochim Biophys Acta 1532: 162-172.

Donoghue PCJ, Benton MJ (2007) Rocks and clocks: calibrating the tree of life using fossils and molecules. Trends Genet 22: 424-431.

Ecroyd H, Belghazi M, Dacheux J-L, Miyazaki M, Yamashita T, Gatti JL (2006) An epididymal form of cauxin, a carboxylesterase-like enzyme, is present and active in mammalian male reproductive fluids. Biol Reprod 74: 439-447.

Emmanuelsson O, Brunak S, von Heijne G, Nielson H (2007) Locating proteins in the cell using TargetP, SignalP and related tools. Nat Protocols 2: 953-971.

Fleming C.D, Bencharit S, Edwards CC, Hyatt JL, Tsurkan L, Bai F, Fraga C, Morton CL, Howard-Williams EL, Potter PM, Redinbo MR (2005) Structural insights into drug processing by human carboxylesterase 1: tamoxifen, Mevaststin, and inhibition by Benzil. J Mol Biol 352: 165-177.

Ghosh S (2000) Cholesteryl ester hydrolase in human monocyte/macrophage: cloning, sequencing and expression of full-length cDNA. Physiol Genomics 2: 1-8.

Ghosh S, Mallonee DH. Grogan W.M. (1995) Molecular cloning and expression of rat hepatic neutral cholesteryl ester hydrolase. Biochim Biophys Acta 1259: 305-312.

Guex N, Peitsch MC (1997) SWISS-MODEL and the Swiss-PdbViewer: An environment for comparative protein modelling. Electrophoresis 18: 2714-2723.

Holmes RS, Chan J, Cox LA, Murphy WJ, VandeBerg JL (2008a) Opossum carboxylesterases: sequences, phylogeny and evidence for CES duplication events predating the marsupial-eutherian common ancestor. BMC Evol Biol 8: 54. 
Holmes RS, Cox LA, VandeBerg JL (2008b) Mammalian carboxylesterase 5: comparative biochemistry and genomics. Comp Biochem Physiol Part D 3: 195-204.

Holmes RS, Glenn JP, VandeBerg JL, Cox LA (2009a) Baboon carboxylesterases 1 and 2: sequences, structures and phylogenetic relationships with human and other primate carboxylesterases. J Med Primatol 38: 27-38.

Holmes RS, VandeBerg JL, Cox LA (2009b) Bovine carboxylesterases: evidence for two CES1 and five families of CES genes on chromosome 18. Comp Biochem Physiol Part D 4: 11-20.

Holmes RS, VandeBerg JL, Cox LA (2009c) Horse carboxylesterases: evidence for six CES1 and four families of CES genes on chromosome 3. Comp Biochem Physiol Part D 4: 54-65.

Holmes RS, VandeBerg JL, Cox LA (2009d) A new class of mammalian carboxylesterase CES6. Comp Biochem Physiol Part D in press.

Horse Genome Project (2008) http://www.uky.edu/Ag/Horsemap/

Horton P, Nakai K (1997) Better prediction of cellular localization sites with the k nearest neighbors classifier. Proc Int Conf Intell Syst Mol Biol 5: 147-152.

Hosokawa M, Furihata T, Yaginuma Y, Yamamoto N, Kayano N, Fujii A, Nagahara Y, Satoh T, Chiba K (2007) Genomic structure and transcriptional regulation of the rat, mouse and human carboxylesterase genes. Drug Metab Revs 39: 1-15.

Humerickhouse R, Lohrbach K, Li L et al (2000) Characterization of CPT-11 hydrolysis by human liver carboxylesterase isoforms h-CE1 and hCE-2. Cancer Res 60: 1189-1192.

Imai T (2006) Human carboxylesterase isozymes: catalytic properties and rational drug design. Drug Metab Pharmacogen 21: 173-185.

Imai T, Yoshigae Y, Hosokawa M et al (2003) Evidence for the involvement of a pulmonary first-pass effect via carboxylesterase in the disposition of a propanolol ester derivative after intravenous administration. $\mathrm{J}$ Pharmacol Exp Therapeut 307: 1234-1242.

International Human Genome Sequencing Consortium (2001) Initial sequencing and analaysis of the human genome. Nature 409: 860-921.

Kent WJ, Sugnet CW, Furey TS et al (2003) The human genome browser at UCSC. Genome Res 12: 994-1006.

Kopp J, Schwede T (2004) The SWISS-MODEL Repository of annotated three-dimensional protein structure homology models. Nucleic Acids Res 32: D230-D234.

Kroetz DL, McBride OW, Gonzalez FJ (1993) Glycosylation-dependent activity of Baculovirus-expressed human liver carboxylesterases: cDNA cloning and characterization of two highly similar enzyme forms.

Biochem 32: 11606-11617.

Langmann T, Becker A, Aslanidis C, Notka F, Ulrich H, Schwer H, Schcmitz G (1997) Structural organization and characterization of the promoter region of a human carboxylesterase gene. Biochim Biophys Acta 1350: 6574.

Leinweber FJ (1987) Possible physiological roles of carboxyl ester hydrolases. Drug Metab Revs 18: 379-439.

Lein ES, Hawrylycz MJ, Ao N, Ayres M, Bensinger A, Bernard A, Boe AF, Boguski MS, Brockway KS, Byrnes EJ, Chen L, Chen L, Chen T-M, Chin MC, Chong J, Crook BE, Czaplinska A, Dang CN, Datta S, Dee NR, Desaki AL, Desta T, Diep E, Dolbeare TA, Donelan MJ, Dong H-W, Dougherty JG, Duncan BJ, Ebbert AJ, Eichele G, Estin LK, Faber C, Facer BA, Fields R, Fischer SR, Fliss TP, Frensley C, Gates SN, Glattfelder KG, Halverson KR, Hart MR, Hohmann JG, Howell MP, Jeung DP, Johnson RA, Karr PT, Kawal R, Kidney JM, Knapik RH, Kuan CL, Lake JH, Laramee AR, Larsen KD, Lau C, Lemon TA, Liang AJ, Liu Y, Luong LT, 
Michaels J, Morgan JJ, Morgan RJ, Mortrud MT, Mosqueda NF, Ng LL, Ng R, Orta GJ, Overly CC, Pak TH, Parry SE, Pathak SD, Pearson OC, Puchalski RB, Riley ZL, Rockett HR, Rowland SA, Royall JJ, Ruiz MJ, Sarno NR, Schaffnit K, Shapovalova NV, Sivisay T, Slaughterbeck CR, Smith SC, Smith KA, Smith BI, Sodt AJ, Stewart NN, Stumpf' K-R, Sunkin SM, Sutram M, Tam A, Teemer CD, Thaller C, Thompson CL, Varnam LR, Visel A, Whitlock RM, Wohnoutka PE, Wolkey CK, Wong VY, Wood M, Yaylaoglu MB, Young RC, Youngstrom BL, Yuan XF, Zhang B, Zwingman' TA, Jones AR (2007) Genome wide atlas of gene expression in the mouse brain. Nature 145: 168-176.

Lockridge O, Adkins S, La Due BN (1987) Location of disulfide bonds within the sequence of human serum cholinesterase. J Biol Chem 262: 12945-12952.

Marsh S, Xiao M, Yu J, Ahluwalia R, Minton M, Freimuth RR, Kwok P-Y, McLeod HL (2004) Pharmacogenomic assessment of carboxylesterases 1 and 2. Genomics 84: 661-668.

McGuffin LJ, Bryson K, Jones DT (2000) The PSIPRED protein structure prediction server. Bioinformatics 16: 404-405.

Mouse Genome Sequencing Consortium (2002) Initial sequencing and comparative analysis of the mouse genome. Nature 420: 520-562.

Miyazaki M, Kamiie K, Soeta S, Taira H, Yamashita T (2003) Molecular cloning and characterization of a novel carboxylesterase-like protein that is physiologically present at high concentrations in the urine of domestic cats (Felis Catus). Biochem J 370: 101-110.

Miyazaki K, Yamashita T, Suzuki Y, Saito Y, Soeta S, Taira H, Suzuki A (2006) A major urinary protein of the domestic cat regulates the production the production of felinine, a putative pheromone precursor. Chem Biol 13: 10171-9.

Munger JS, Shi GP, Mark EA, Chin DT, Gerard C, Chapman HA (1991) A serine esterase released by human alveolar macrophages is closely related to liver microsomal carboxylesterases. J Biol Chem 266: 18832-18838.

Ohtsuka K, Inoue S, Kameyama M (2003) Intracellular conversion of irinotecan to its active form, SN-38, by native carboxylesterase in human non-small cell lung cancer. Lung Cancer 41: 87-198.

Ota, T., Suzuki, Y., Nishikawa, T., Otsuki, T., Sugiyama, T., Irie, R.,Wakamatsu, A., Hayashi, K., Sato, H., Nagai,K., Kimura, K.,Makita, H.,Sekine,M., Obayashi,M., Nishi, T., Shibahara, T., Tanaka, T., Ishii, S., Yamamoto, J., Saito, K., Kawai, Y., Isono, Y., Nakamura, Y., Nagahari, K., Murakami, K., Yasuda, T., Iwayanagi, T.,Wagatsuma,M., Shiratori, A., Sudo, H., Hosoiri, T., Kaku, Y., Kodaira, H., Kondo, H., Sugawara,M., Takahashi,M., Kanda, K., Yokoi, T., Furuya, T., Kikkawa, E., Omura, Y., Abe, K., Kamihara, K., Katsuta, N., Sato, K., Tanikawa, M., Yamazaki,M., Ninomiya,K., Ishibashi, T., Yamashita, H.,Murakawa,K., Fujimori,K., Tanai, H., Kimata, M., Watanabe, M., Hiraoka, S., Chiba, Y., Ishida, S., Ono, Y., Takiguchi, S., Watanabe, S., Yosida,M., Hotuta, T., Kusano, J., Kanehori, K., Takahashi-Fujii, A., Hara, H., Tanase, T.O., Nomura, Y., Togiya, S., Komai, F., Hara, R., Takeuchi, K., Arita, M., Imose,N., Musashino, K., Yuuki, H., Oshima, A., Sasaki, N., Aotsuka, S., Yoshikawa, Y., Matsunawa, H., Ichihara, T., Shiohata, N., Sano, S., Moriya, S., Momiyama, H., Satoh, N., Takami, S., Terashima, Y., Suzuki, O., Nakagawa, S., Senoh, A., Mizoguchi, H., Goto, Y., Shimizu, F., Wakebe, H., Hishigaki, H., Watanabe, T., Sugiyama, A., Takemoto, M., Kawakami, B., Yamazaki, M., Watanabe, K., Kumagai, A., Itakura, S., Fukuzumi, Y., Fujimori, Y., Komiyama,M., Tashiro, H., Tanigami, A., Fujiwara, T., Ono, T., Yamada, K., Fujii, Y., Ozaki, K., Hirao, M., Ohmori, Y., Kawabata, A., Hikiji, T., Kobatake, N., Inagaki, H., Ikema, Y., Okamoto, S., Okitani, R., Kawakami, T., Noguchi, S., Itoh, T., Shigeta, K., Senba, T., Matsumura, K., Nakajima, Y.,Mizuno, T.,Morinaga,M., Sasaki, M., Togashi, T.,Oyama, M., Hata,H.,Watanabe,M.,Komatsu, T.,Mizushima-Sugano, J., Satoh, T., Shirai, Y., Takahashi, Y.,Nakagawa, K.,Okumura,K.,Nagase, T.,Nomura,N., Kikuchi, H.,Masuho, Y., Yamashita, R., Nakai, K., Yada, T., Nakamura, Y., Ohara, O., Isogai, T., Sugano, S., 2004. Complete sequencing and characterization of 21,243 full-length human cDNAs. Nat. Genet. 36, 40-45. 
Pindel EV, Kedishvili NY, Abraham TL, Brezinski MR, Zhang A, Dean RA, Bosron WF (1997) Purification and cloning of a broad substrate specificity human liver carboxylesterase that catalyzes the hydrolysis of cocaine and heroin. J Biol Chem 272: 14769-14775.

Potter P.M, Wolverton JS, Morton CL, Wierdl M, Danks MK (1998) Cellular localization domains of a rabbit and human carboxylesterase: influence on irinotecan (CPT-11) metabolism by the rabbit enzyme. Cancer Research 58: 3627-32.

Redinbo MR, Potter PN (2005) Mammalian carboxylesterases: from drug targets to protein therapeutics. Drug Discovery Today 10: 313-20.

Ring J, Seifert J, Brendel W (1977) High incidence of horse serum protein allergy in various autoimmune disorders. J Allergy Clin Immunol 59: 185-189.

Robbi M, Beaufay H (1991) The COOH terminus of several liver carboxylesterases targets these enzymes to the lumen of the endoplasmic reticulum. J Biol Chem 266: 20498-20503.

Ruppert C, Bagheri A, Markart P, Schmidt R, Seegar W, Gunther A (2006) Liver carboxylesterase cleaves surfactant protein (SP-B) and promotes surfactant subtype conversion. Biochem Biophys Res Coms 348: 14491454.

Sanghani SP, Quinney SK, Fredenberg TB, Davis WI, Murray DJ, Bosron WF (2004) Hydrolysis of irinotecan and its oxidative metabolites, 7-ethyl-10-[4-N(5-aminopentanoic acid)-1-piperidino] carbonyloxycampothecin and 7-ethyl-10-[4-(1-piperidino)-1 amino]-carbonyloxycamptothecin, by human carboxylesterases CES1A1, CES2, and a newly expressed carboxylesterase isoenzyme, CES3. Drug Metab Dispos 32: 505-511.

Satoh T, Hosokawa M (1998) The mammalian carboxylesterases: from molecules to functions. Ann Revs Pharmacol Toxicol 38: 257-288.

Satoh T, Hosokawa M (2006) Structure, function and regulation of carboxylesterases. Chem-Biol Interactions 162: 195-211.

Satoh H, Taylor P, Bosron WF, Sanghani P, Hosokawa M, Du PB (2002) Current progress on esterases: from molecular structure to function. Drug Metab Dispos 30: 488-493.

Schewer H, Langmann T, Daig R, Becker A, Aslandis C, Schmidt G (1997) Molecular cloning and characterization of a novel putative carboxylesterase, present in human intestine and liver. Biochem Biophys Res Commun 233: 117-120.

Schwede T, Kopp J, Guex N, Peitsch MC (2003) SWISS-MODEL: an automated protein homology-modeling server. Nucleic Acids Research 31: 3381-3385.

Shibita F, Takagi Y, Kitajima M, Kuroda T, Omura T (1993) Molecular cloning and characterization of a human carboxylesterase gene. Genomics 17: 76-82.

Tang,X, Wu H, Wu Z, Wang G, Zhu D (2008) Carboxylesterase 2 is downregulated in colorectal cancer following progression of the disease. Cancer Invest 26: 178-181.

Thierry-Mieg D, Thierry-Mieg J (2006) AceView: A comprehensive cDNA-supported gene and transcripts annotation. Genome Biology 7, S12 http://www.ncbi.nlm.nih.gov/IEB/Research/Acembly/index.html?human

Tsujita T, Okuda H (1993) Palmitoyl-coenzyme A hydrolyzing activity in rat kidney and its relationship with carboxylesterase. J Lipid Res 34: 1773-1781.

von Heijne G (1983) Patterns of amino acids near signal-sequence cleavage sites. European Journal of Biochem 133: $17-21$ 
Wang H, Gilham D, Lehner R (2007) Proteomic and lipid characterization of apo-lipoprotein B-free luminal lipid droplets from mouse liver microsomes: implications for very low density lipoprotein assembly. J Biol Chem 282: 33218-33226.

Woodburne MO, Rich TH, Springer MS (2003) The evolution of tribospheny and the antiquity of mammalian clades. Mol Phylogenet Evol 28: 360-385.

Xu G, Zhang W, Ma, MK, MacLeod HL (2002) Human carboxylesterase 2 is commonly expressed in tumor tissue and is correlated with the activation of irinotecan. Clin Cancer Res 8: 2605-2611.

Zhen L, Rusiniak ME, Swank RT (1995) The beta-glucuronidase propeptide contains a serpin-related octamer necessary for complex formation with egasyn esterase and for retention within the endoplasmic reticulum. J Biol Chem 270: 11912-11920. 
Exop 1 signal poptide

Exan 2

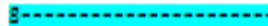

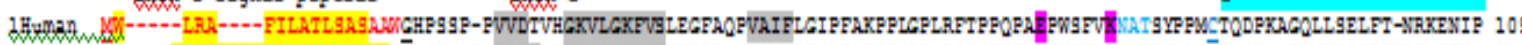

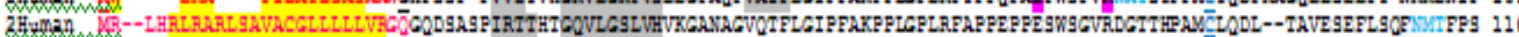

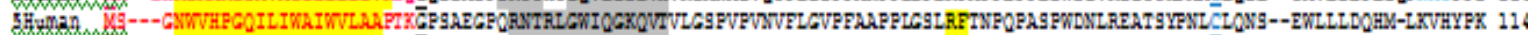

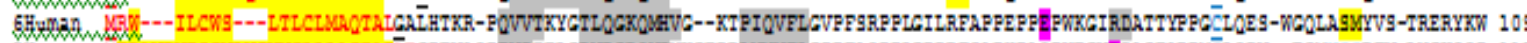

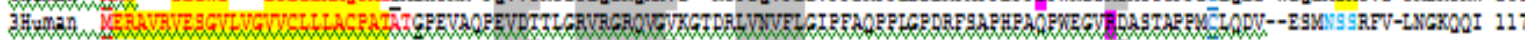

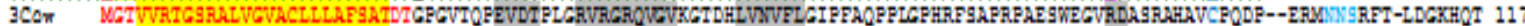

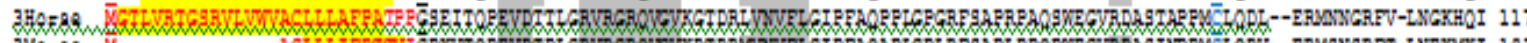

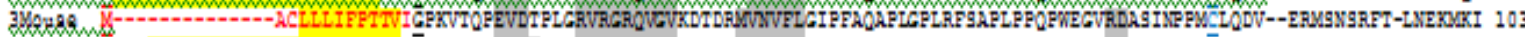

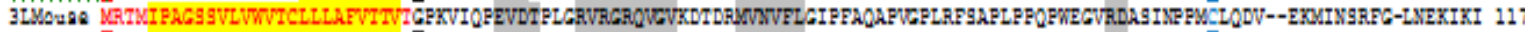

- $3 x \sin ^{2}$ Exan 4 Zxpan 5

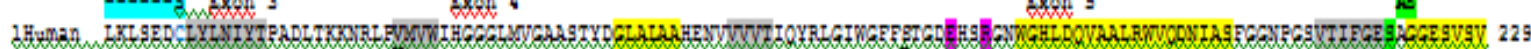

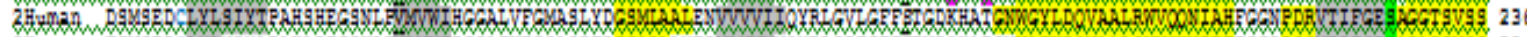

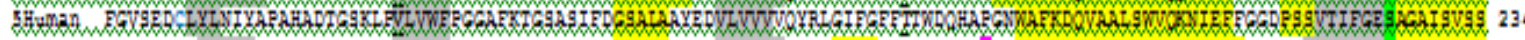

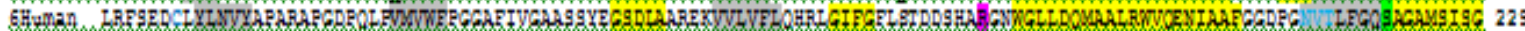

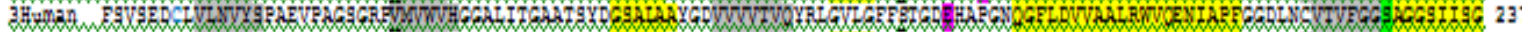

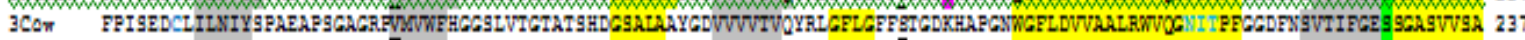

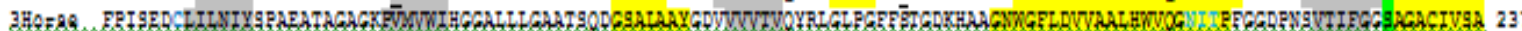

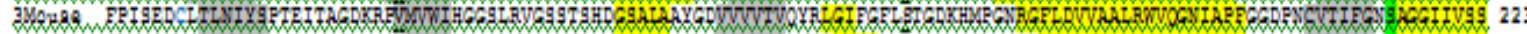

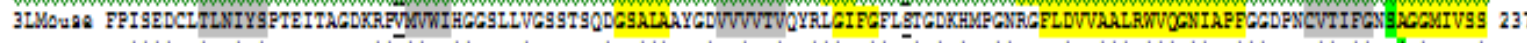

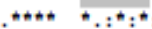

ExAn 6

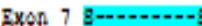

$\operatorname{sen} 8$ Exsin 9

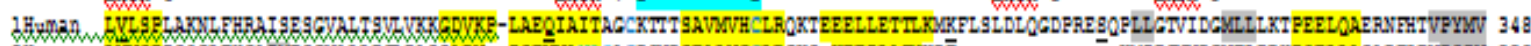

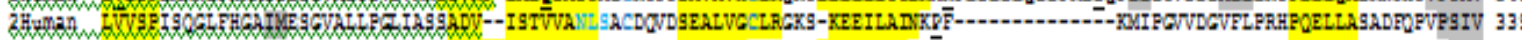

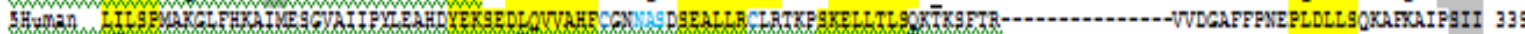

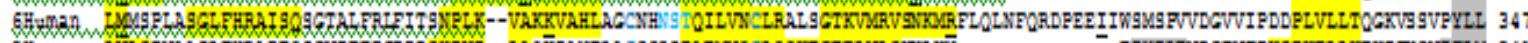

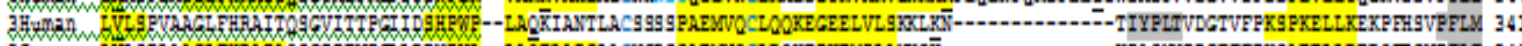

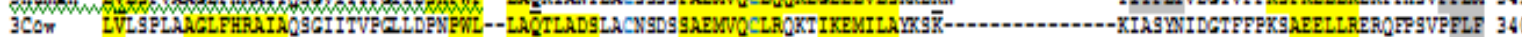

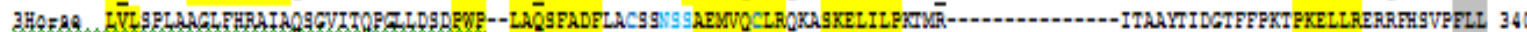

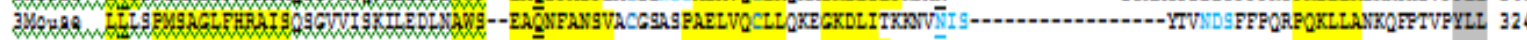

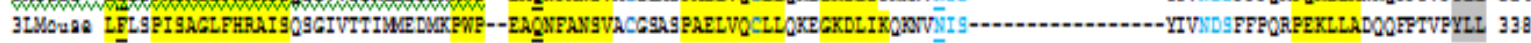
Diti:
Ris 810 :
Zxan 10
$\sin 11$
$\therefore .+$. $^{*} \cdot:^{*}$

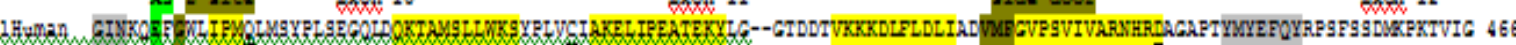

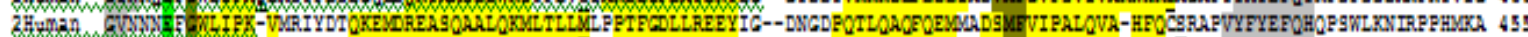
IH

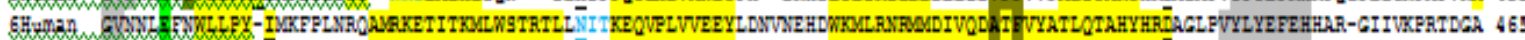

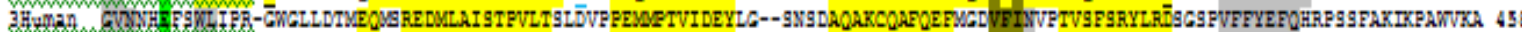

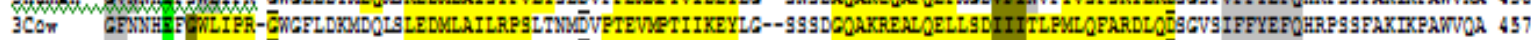

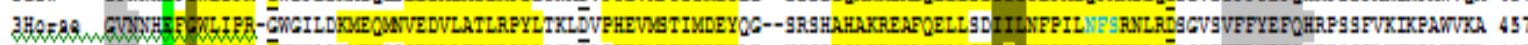
3Mgre GTWF

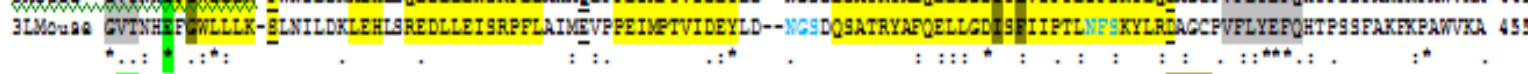

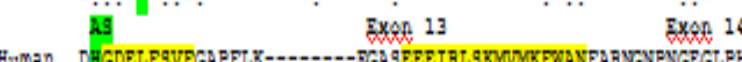

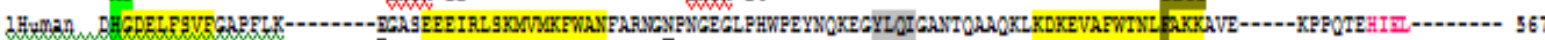

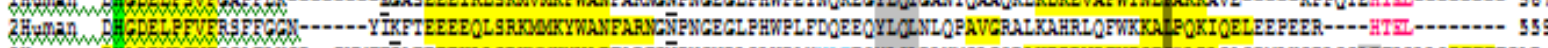

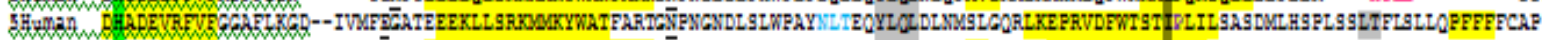

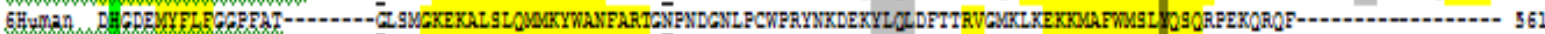

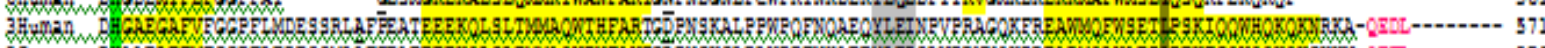

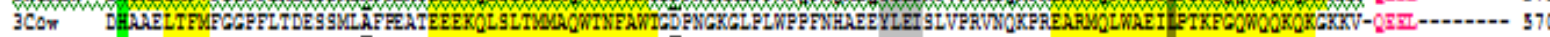

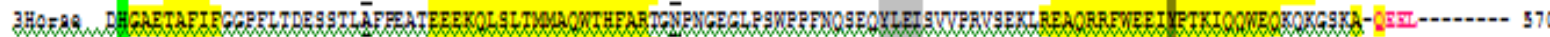

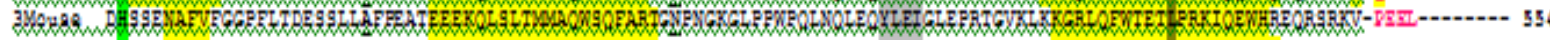

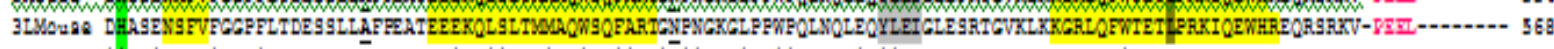

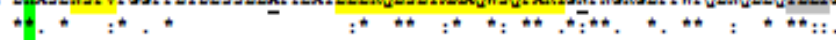

Figure 1: Amino Acid Sequence Alignments for Mammalian CES3 and Human CES1, CES2, CES5 and CES6 Subunits

See Table 1 for sources of CES sequences; * shows identical residues for CES subunits; : similar alternate residues; . dissimilar alternate residues; Residues involved in endoplasmic reticulum processing at $\mathrm{N}$ - (Signal peptide) and C- termini (MTS-microsomal (endoplasmic reticulum) targeting sequence); N-glycosylation residues at 79 NAT (Human CESI) and potential N-glycosylation sites; active site (AS) triad residues Ser; Glu; and His. 'Side door', 'Gate' residues and Cholesterol binding Gly residue ( $\mathbf{z}$ site) for human CES1 Disulfide bond Cys residues for human CES1: S---S. Charge clamp residues identified for human CES1; Helix (Human CES1 or predicted helix; Sheet (Human CES1) or predicted sheet. Bold font shows known or predicted exon junctions. Exon numbers refer to human CES1 gene. 


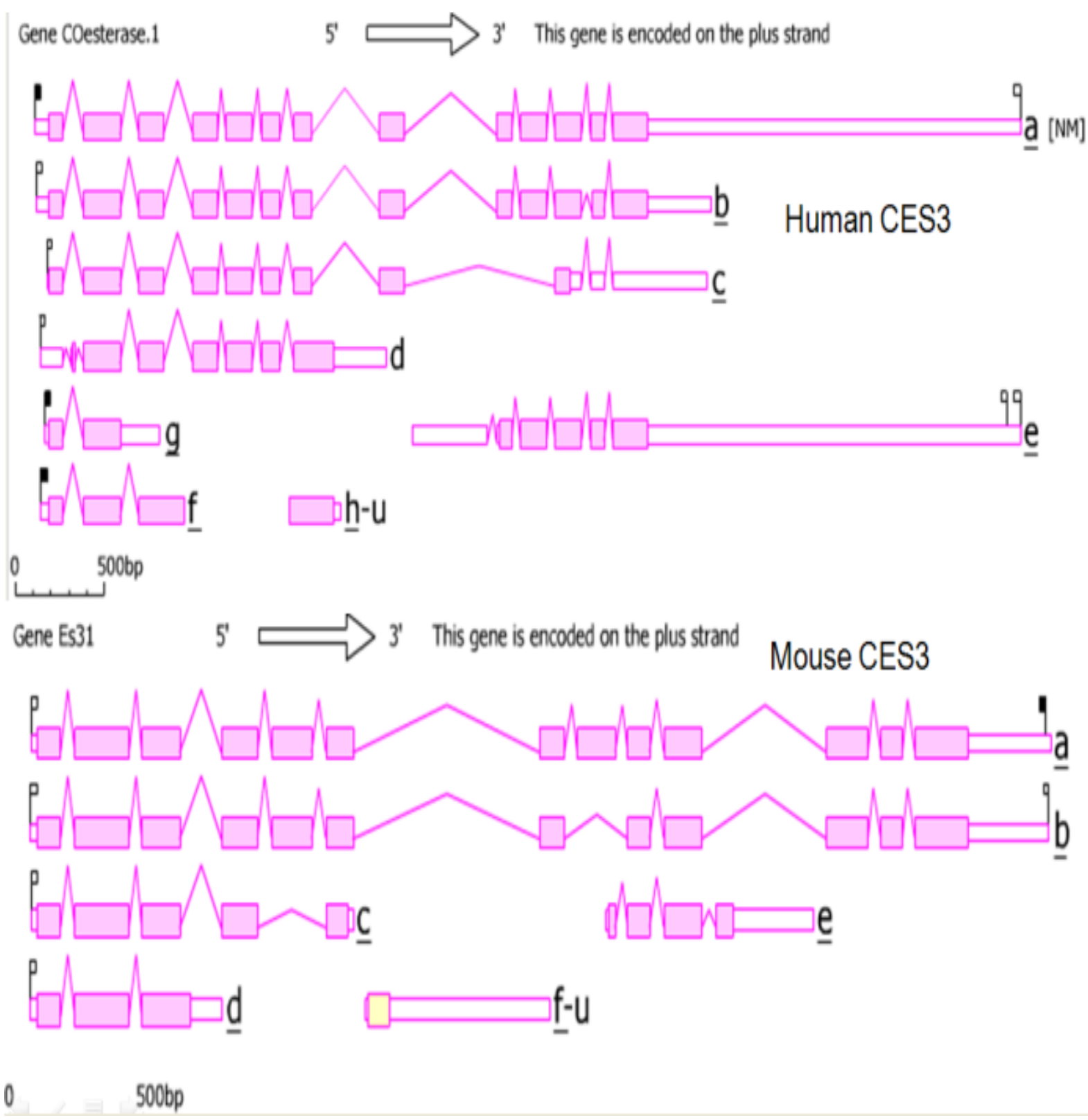

Figure 2: Gene Structures and Splicing Variants for the Human CES3 (NM024922) and the Mouse CES3 (BC061004) Genes.

Derived from AceView website (Thierry-Mieg and Thierry-Mieg,2006)

http://www.ncbi.nlm.nih.gov/IEB/Research/Acembly/ Mature isoform variants (a,b,c etc) are shown with capped $5^{\prime}-$ and $3^{\prime}-$ ends for the predicted mRNA sequences. Gene Coesterase 1 refers to human CES3 gene; Gene Es31 refers to mouse CES3 gene. 


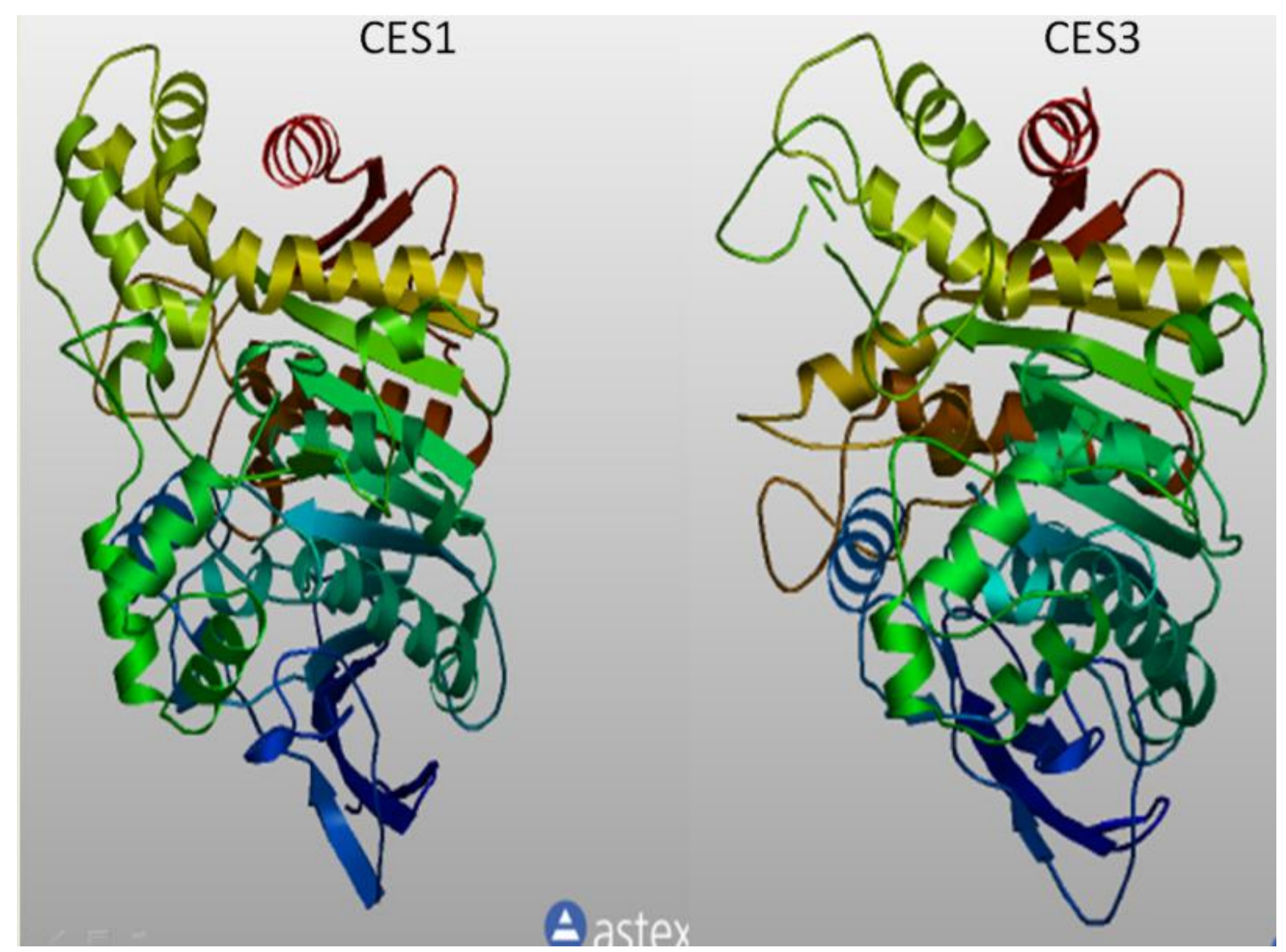

Figure 3: Tertiary Structure for Human CES1 Subunit and Predicted Tertiary Structure for Human CES3 Subunit.

The structure for human CES1 is taken from Bencharit et al, 2003. Predicted human CES3 3-D structure was obtained using the SWISS MODEL web site

http://swissmodel.expasy.org/workspace/index.php? And the reported amino acid sequence

(Sanghani et al.,2004). The rainbow color code describes the 3-D structures from the N- (blue) to C-termini (red color). 
Exon 2998 identical

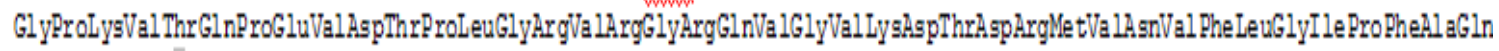

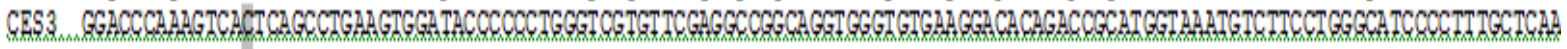

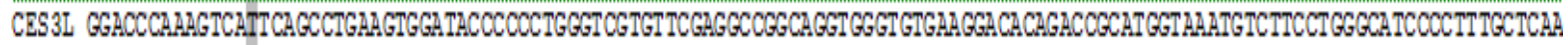

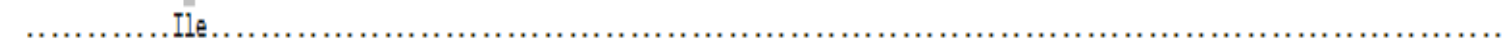

A1 aProLeuGlyProLeuArgPheSerA1 aProLeuProProGinProTrpGluGlyValArgAgpAla SerIl eAsnProProlet

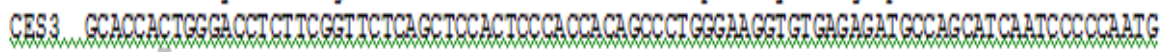
CBS3L GCACCAGIGGGACCTCTTCGGITCTCAGCTCCACTCCCACCACAGCCCTGGGAMGGIGIGAGAGAIGCCAGCAICAITCCCCAIIG .......Val. ....

\section{Intron 2858 identical}

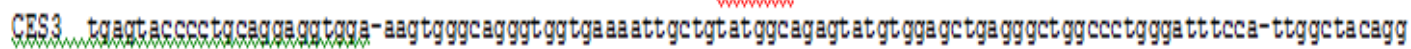
CBS3L tgagtaccectgcagtaagtgggcaagtgtgcagggtagtggca gtctctggatgecagggt atgtggagetga ggget ggecetgaaatt tcecettggetgcagg

Exon 3998 identical

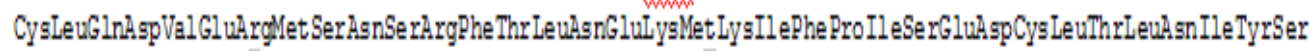

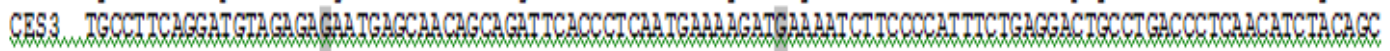

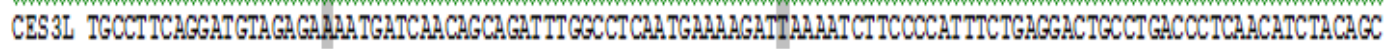

$$
\text { ................... Lys....... }
$$
Ile.

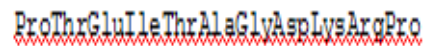

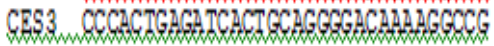
CES3L CCCACTGAGATCACTGCAGGGGACAMAIGGCCG

Intron 3948 identical

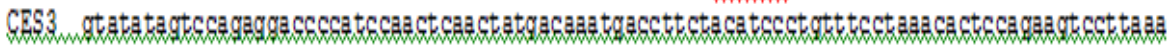
CES3L gtata tagtcca gagga cccca tccaa ctcga ctatgacaaa tgaccttcta ca cecetgtt tcctaaa cactcca gaagt tet ta ta

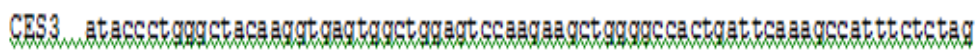

CBS3L ataccetggget aca aggggggtggctggagt ccasgagctggggeca ctgat tca a gecatttctctag

Exop 4978 identical

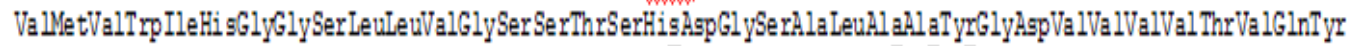

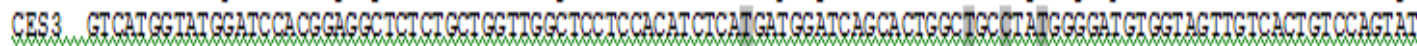

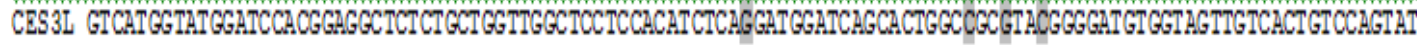
....

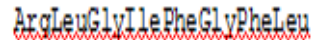

CES3 CGCCTGGSATCTTGGTTCCTC

CES3L CGCCTTGGATCTTIGGCTTCCTC

Figure 4: Nucleotide Sequence Alignments for Mouse CES3 'Like' Genes: CES3 (Es31) and CES3L (ES31L): Predicted Exons 2-4; and Predicted Introns 2 and 3.

Exon sequences are in CAPITALS and intron sequence in lower case. Note the different percentages of sequence identities for exon 2-4, (98\%); introns 2-3 (92\%). Nucleotide substitutions are shaded. The deduced amino acid sequence for exons $2-4$ of mouse CES3 is shown as well as any deduced amino acid substitutions observed for CES3L. 

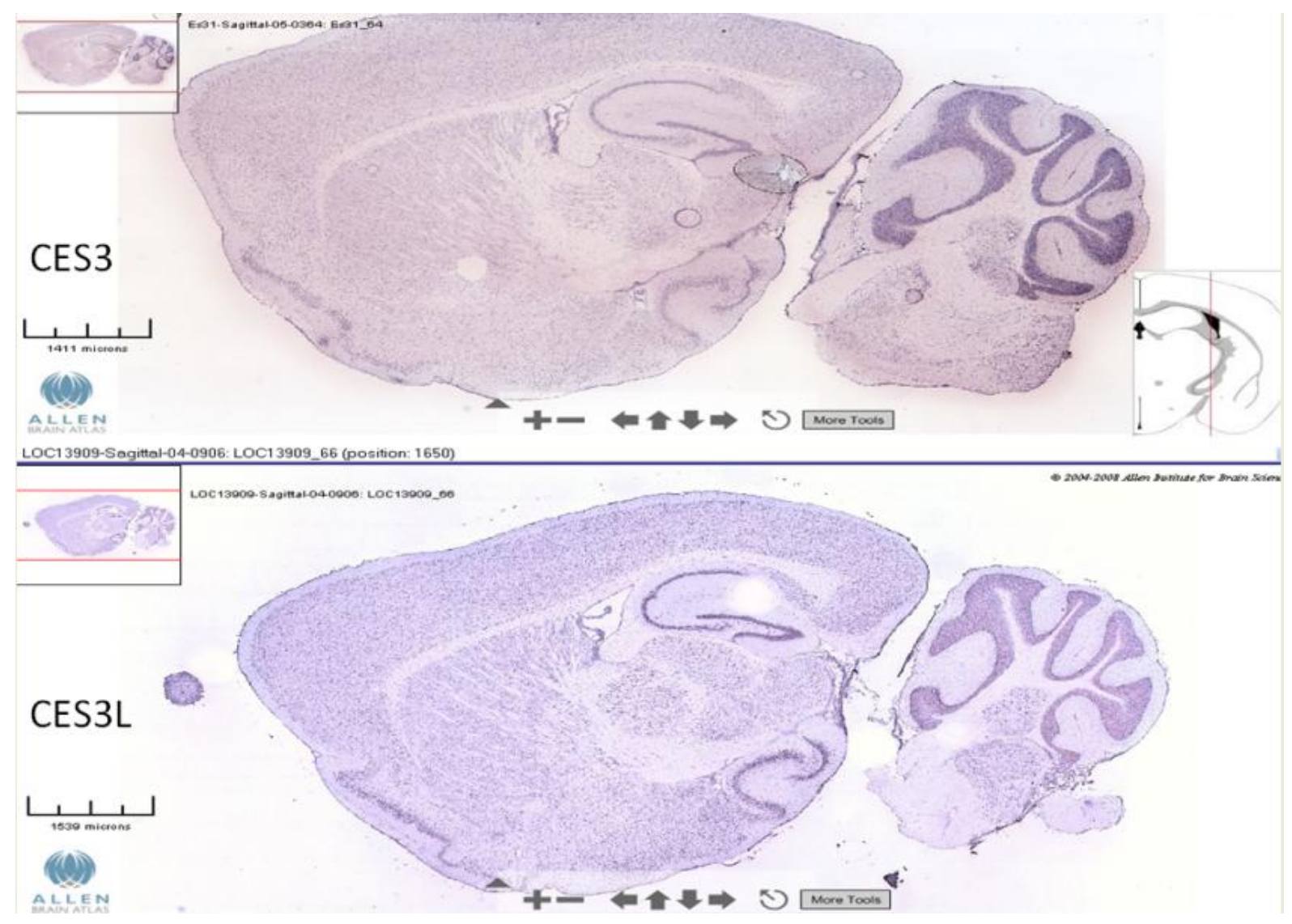

Figure 5: Sagittal section of mouse brain showing the distribution of mouse CES3 and CES3L transcripts.

The two distinct regions of the mouse brain (C57BL6/6J strain) included the cerebellum (right and the cerebrum (left). Note major staining of CES3 and CES3L transcripts in the cerebellum folds and the hippocampus and amygdalar nuclei regions of the cerebrum. The sections were obtained from the Allen Brain Atlas web site (http://www.brain-map.org) (Lein et al., 2007) using the GenBank IDs BC061005 and BC019147, respectively. 


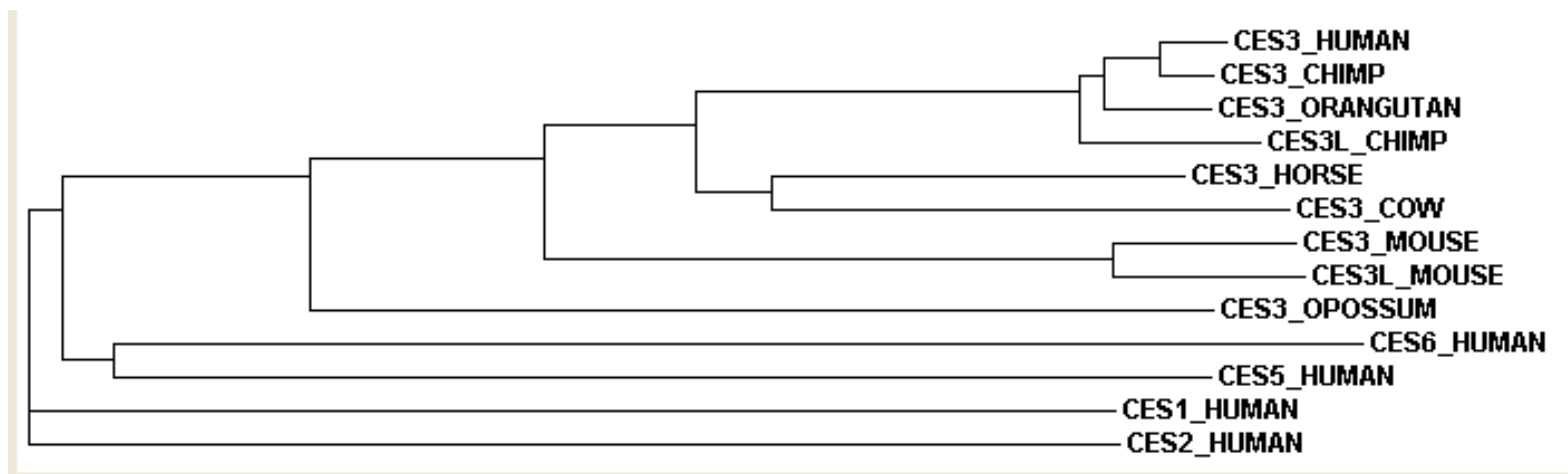

Figure 6: Phylogenetic Tree of Mammalian CES3 and Human CES1, CES2, CES5 and CES6 Amino Acid Sequences.

The tree is labeled with the gene name and the name of the mammal. Note the major cluster for mammalian CES3 'like' sequences and the separation of these sequences from human CES1, CES2, CES5 and CES6 sequences. The gene duplication events generating the five distinct gene families (CES1, CES2, CES3, CES5 and CES6) have been previously estimated to have occurred 328-378 million years ago (Holmes et al., 2008a). 


\begin{tabular}{|c|c|c|c|c|c|c|c|c|c|c|}
\hline Mammal & CES & GenBank ID & UNIPROT & No of & Chromosome & Strand & ${ }^{4} \mathrm{CES}$ Gene order & Gene & $\begin{array}{l}\text { No. } \\
\text { of }\end{array}$ & ${ }^{3} \mathrm{pI}$ \\
\hline & Gene & *RefSeq NCBI & ID & Amino & Location & & & Size & Exons & \\
\hline & & Accession No. & & Acids & & & & (bps) & & \\
\hline Human & CES 3 & $\mathrm{BC} 053670$ & Q6UWW8 & 571 & $\begin{array}{c}16: 65,552,639- \\
65,566,552 \\
16: 66,682,109-\end{array}$ & Positive & $\begin{array}{l}\text { CES2-CES3-CES6 } \\
\text { CES6-CES3L-CES2- }\end{array}$ & 13,913 & 13 & 5.4 \\
\hline Chimp & CES 3 & *XP_511224 & & 571 & $66,695,987$ & Positive & $\begin{array}{c}\text { CES3 } \\
\text { CES6-CES3L-CES2- }\end{array}$ & 13,879 & 13 & 5.7 \\
\hline Chimp & CES3L & *XP_001173132 & & 479 & $\begin{array}{c}16: 5,892,348-5,905,878 \\
16: 54,242,602-\end{array}$ & Positive & CES3 & 13,531 & 11 & 6.6 \\
\hline Orangutan & CES3 & CR857194 & Q5RCL7 & 569 & $54,266,316$ & Positive & CES3-CES2-CES6 & 23,714 & 13 & 6.4 \\
\hline Horse & CES3 & *XP_001496251 & & 570 & $\begin{array}{c}3: 17,417,834-17,428,268 \\
18: 33,671,230-\end{array}$ & Positive & CES2-CES3-CES6 & 10,434 & 13 & 6.3 \\
\hline Cow & CES3 & *XP_590749 & & $\begin{array}{l}570 \\
554\end{array}$ & $33,683,956$ & Positive & CES2-CES3-CES6 & 12,727 & 13 & 5.6 \\
\hline Mouse & CES 3 & ВC061004 & Q63880 & 554 & $\begin{array}{c}8: 107,572,572- \\
107,582,000 \\
8: 107,607,684-\end{array}$ & Positive & $\begin{array}{c}{ }^{\wedge} \mathrm{CES} 2-\mathrm{CES3}-\mathrm{CES3L-} \\
\text { CES6 } \\
{ }^{\wedge} \mathrm{CES} 2-\mathrm{CES} 3-\mathrm{CES3L}-\end{array}$ & 9,429 & 13 & 5.9 \\
\hline Mouse & CES3L & ВC019147 & & 568 & $\begin{array}{c}107,617,159 \\
1: 677,687,773-\end{array}$ & Positive & CES6 & 9,476 & 13 & 5.7 \\
\hline Opossum & CES3 & *XP_001372405 & & 571 & $677,741,087$ & Negative & ${ }^{\wedge} \mathrm{CES} 2-\mathbf{C E S 3 - C E S 6}$ & 53,315 & 13 & 5.6 \\
\hline Human & CESI & L07765 & $\mathrm{P} 23141$ & 567 & $\begin{array}{c}16: 54,394,265- \\
54,424,576 \\
16: 65,525,828-\end{array}$ & Negative & CES4-CES1-CES5 & 30,311 & 14 & 6.2 \\
\hline Human & CES2 & BX538086 & 000348 & 559 & $\begin{array}{c}65,536,493 \\
16: 54,437,867-\end{array}$ & Positive & CES2-CES3-CES6 & 10,665 & 12 & 5.7 \\
\hline Human & CES5 & BC069501 & Q6NT32 & 575 & $\begin{array}{c}54,466,634 \\
16: 65,580,134-\end{array}$ & Negative & CES4-CES1-CES5 & 28,767 & 13 & 6 \\
\hline Human & CES 6 & FLJ37464 & Q6UX55 & 545 & $65,602,403$ & Positive & CES2-CES3-CES6 & 22,269 & 14 & 9.4 \\
\hline
\end{tabular}

Table 1: Mammalian CES3 and Human CES1, CES2, CES5 and CES6 Genes and Subunits.

*RefSeq NCBI Sequence; ^the mouse and opossum genomes contain multiple contiguous CES2 genes; ${ }^{1}$ extracellular and/or cell wall location; ${ }^{2}$ ER: endoplasmic reticulum location; ${ }^{3}$ pI refers to predicted isoelectric point. ${ }^{4}$ CES gene in bold refers to the specific gene among the contiguous CES genes. 


\begin{tabular}{|c|c|c|c|c|c|c|c|c|c|c|c|c|c|}
\hline CESGene & Human CES3 & Chimp CES3 & Orang CES3 & Chimp CES3L & Horse CES3 & Cow CES3 & Mouse CES3 & Mouse CES3L & Opossum CES3 & Human CESI & Human CES2 & Human CES5 & Human CES6 \\
\hline Human CES3 & 100 & 97 & 94 & 92 & 77 & 73 & 68 & 68 & 58 & 47 & 50 & 48 & 45 \\
\hline Chimp CES3 & 97 & 100 & 95 & 92 & 78 & 75 & 68 & 68 & 58 & 47 & 50 & 48 & 44 \\
\hline OrangCES3 & 94 & 95 & 100 & 93 & 78 & 74 & 68 & 68 & 58 & 47 & 50 & 48 & 44 \\
\hline Chimp CES3L & 92 & 92 & 93 & 100 & 76 & 73 & 67 & 67 & 58 & 46 & 49 & 48 & 43 \\
\hline Horse CES3 & 77 & 78 & 78 & 76 & 100 & 79 & 68 & 68 & 61 & 49 & 50 & 49 & 43 \\
\hline Cow CES3 & 73 & 75 & 74 & 73 & 79 & 100 & 66 & 65 & 60 & 47 & 47 & 47 & 41 \\
\hline Mouse CES3 & 68 & 68 & 68 & 67 & 68 & 66 & 100 & 91 & 57 & 45 & 48 & 48 & 43 \\
\hline Mouse CES3L & 68 & 68 & 68 & 67 & 68 & 65 & 91 & 100 & 56 & 45 & 47 & 47 & 43 \\
\hline Opossum CES3 & 58 & 58 & 58 & 58 & 61 & 60 & 57 & 56 & 100 & 49 & 49 & 48 & 45 \\
\hline Human CES1 & 47 & 47 & 47 & 46 & 49 & 47 & 45 & 45 & 49 & 100 & 51 & 49 & 46 \\
\hline Human CES2 & 50 & 50 & 50 & 49 & 50 & 47 & 48 & 47 & 49 & 51 & 100 & 48 & 44 \\
\hline Human CES5 & 48 & 48 & 48 & 48 & 49 & 47 & 48 & 47 & 48 & 49 & 48 & 100 & 47 \\
\hline Human CES6 & 45 & 44 & 44 & 43 & 43 & 41 & 43 & 43 & 45 & 46 & 44 & 47 & 100 \\
\hline
\end{tabular}

Table 2: Percentage identities for mammalian CES3 and human CES1, CES2, CES5 and CES6 subunit amino acid sequences. 


\begin{tabular}{|c|c|c|c|c|c|c|c|c|c|c|c|c|c|c|c|c|c|}
\hline Mammal & CES & Site 1 & Site 2 & Site 3 & Site 4 & Site 5 & Site 6 & Site 7 & Site 8 & Site 9 & Site 10 & Site 11 & Site 12 & Site 13 & Site 14 & Site 15 & No of \\
\hline & Gene & & & & & & & & & & & & & & & & sites \\
\hline \multirow[t]{4}{*}{ Human } & CES1 & 79NAST & & & & & & & & & & & & & & & 1 \\
\hline & CES2 & & \multicolumn{3}{|c|}{ 111NMT } & & \multicolumn{2}{|l|}{ 276NLS } & & & & & & & & & 2 \\
\hline & CES5 & & & & & & & 281NAS & & & & 358NLS & & & & 513NLT & 3 \\
\hline & CES6 & & & & & 214NVT & & \multicolumn{3}{|c|}{ 276NST } & & & $370 \mathrm{NIT}$ & & & & 3 \\
\hline Human & CES3 & & $105 \mathrm{NSS}$ & & & & & & & & & & & & & & 1 \\
\hline Cow & CES3 & & $105 \mathrm{NSS}$ & & 212NIT & & & & & & & & & & & & 2 \\
\hline Horse & CES3 & & & & 212NIT & & & \multicolumn{3}{|c|}{ 284NSS } & & & & & 423NFS & & 3 \\
\hline Mouse & CES3 & & & & & & & & & $295 \mathrm{NIS}$ & 301NDS & & & 381NGS & & & 3 \\
\hline Mouse & CES3L & & & & & & & & & $309 \mathrm{NIS}$ & $323 \mathrm{NDS}$ & & & 395NGS & 421NFS & & 4 \\
\hline
\end{tabular}

Table 3: Predicted N-glycosylation sites for mammalian CES3 and human CES1, CES2, CES5 and CES6 subunits.

The identified N-glycosylation site is for human CES1 (Kroetz et al., 1993). Amino acid residues are shown for potential N-glycosylation sites: N-Asn; A-Ala; T-Thr; S-Ser; M-Met; LLeu; D-Asp; G-Gly; F-Phe; I-Ile. 


\begin{tabular}{|c|c|c|c|c|}
\hline N-signal & Predicted & Tissue Distribution & $\begin{array}{l}\text { Predicted } \\
\text { CES type }\end{array}$ & GenBank \\
\hline Peptide & Subcellular & (mRNA Frequency) & B & ID \\
\hline $\begin{array}{l}\text { (location) } \\
\text { yes (26- }\end{array}$ & Location & & Domain & \\
\hline 27) & Secreted or extracellular & colon (8), breast, trachea (4) brain, placenta, rectum (2) & yes & NM024922 \\
\hline $\begin{array}{c}\text { yes (26- } \\
27)\end{array}$ & Secreted or extracellular & colon (10) trachea (6) brain, breast (5) placenta (4) testis (3) & yes & BC053670 \\
\hline $\begin{array}{c}\text { yes }(26- \\
27)\end{array}$ & Secreted or extracellular & colon (10) trachea (6) brain breast (5) placenta (4) testis (3) & yes & CR618303 \\
\hline no & Cytosol & ovary, teratocarcinoma, stomach, trachea (1) & yes & *DB232966 \\
\hline $\begin{array}{c}\text { no } \\
\text { yes }(26-\end{array}$ & Extracellular & colon (5), nerve tumor, uterus, brain (2) & yes & АК025389 \\
\hline 27) & Extracellular & bladder, uterus (1) & yes & DA040317 \\
\hline yes (26- & & & & \\
\hline 27) & Extracellular & trachea (1) & yes & DB215224 \\
\hline no & Extracellular & stomach (1) & no & AW813514 \\
\hline
\end{tabular}

\section{Table 4: Tissue distribution of human mRNA transcripts and predicted} encoded CES3 isoforms.

Predicted CES3 gene sizes (kilobases); CES type B domain refers to the presence of essential amino acids at the CES active site; N-signal peptide location refers to the predicted site of hydrolysis for the N-terminal peptide involved in intracellular CES3 processing. Note the higher frequencies for CES3a, CES3b and CES3C expressed in colon, trachea and breast tissue. * refers to a partial mRNA sequence. 